\title{
Distribution of axial length, anterior chamber depth, and corneal curvature in an aged population in South China
}

\author{
Hui Chen, Haotian Lin, Zhuoling Lin, Jingjing Chen and Weirong Chen*
}

\begin{abstract}
Background: Ocular biometry is important for preoperative assessment in cataract and anterior segment surgery. The purpose of this study was to investigate normative ocular biometric parameters and their associations in an older Chinese population.

Methods: This was a cross-sectional observational study. From 2013 to 2014, we recruited inhabitants aged 50 years or older in Guangzhou, China. Among 1,117 participants in the study, data from 1,015 phakic right eyes were used for analyses. Ocular parameters including axial length (AL), anterior chamber depth (ACD), and corneal curvature $(K)$ were measured using an IOL Master.

Results: The mean AL, ACD, and K were 23.48 mm [95 \% confidence interval (Cl), 23.40-23.55], 3.03 mm (Cl, 3.01-3.05), and $44.20 \mathrm{~mm}(\mathrm{Cl}, 44.11-44.29)$, respectively. A mean reduction in ACD with age was observed $(P=0.002)$ in male subjects but not in female subjects $(P=0.558)$. Male subjects had significantly longer ALs ( $23.68 \mathrm{~mm}$ versus $23.23 \mathrm{~mm}$, $P<0.001)$, deeper ACDs ( $3.13 \mathrm{~mm}$ versus $2.95 \mathrm{~mm}, P<0.001)$, and flatter $\mathrm{Ks}(43.85 \mathrm{D}$ versus $44.50 \mathrm{D}, P<0.001)$ than female subjects. Eyes with axial elongation had a flatter cornea $(r=-0.437, P<0.001)$ and a deeper anterior chamber $(r=0.652, p<0.001)$. The ACD was correlated with $\mathrm{K}(r=-0.266, P<0.001)$.

Conclusions: These data provide normative values for $A L, A C D$, and $K$ using the IOL Master for a population in South China. The AL in this Chinese cohort was greater than that observed in the Singaporean Chinese but smaller than that observed in Malaysia and for Caucasians. The Chinese have a shallower ACD than some other racial groups. Age and sex were the most consistent predictors of ocular biometry in the older population from South China.
\end{abstract}

Keywords: Axial length, Anterior chamber depth, Corneal curvature

\section{Background}

Axial length (AL) is one of the basic anatomical parameters in ophthalmology, and a major variable for refractive error and for diagnosing certain pathological conditions such as staphyloma and the risk of retinal detachment before refractive surgery [1-5]. Cataract surgery has become one of the most commonly performed surgical procedures worldwide, and AL and other ocular biometrics such as anterior chamber depth (ACD) and corneal curvature (K) are considered the most important determinants for accurate intraocular lens (IOL) power calculations.

\footnotetext{
* Correspondence: chenwr_q@aliyun.com

State Key Laboratory of Ophthalmology, Zhongshan Ophthalmic Center, Sun Yat-sen University, Guangzhou, Guangdong 510060, China
}

Determination of the normal range of these parameters will provide ophthalmologists with important information that can lead to an improvement in cataract surgical outcomes.

In our recent study of the adult Chinese population before cataract surgery, we reported that the standard deviation of the AL in this cohort was lower than European populations. Furthermore, there was no statistically significant difference in AL between age groups [6]. However, the study was clinic based, and may not be representative of the entire population.

To avoid the potential selection bias present in specific and highly selective patient groups, we now describe the distribution of $\mathrm{AL}$ and its associations with ocular 
biometric parameters measured with the IOL Master in a community-based survey. These data will provide comprehensive age and sex normative data for this instrument in the older South China population.

\section{Methods}

\section{Study population}

In this population-based, cross-sectional study, subjects older than 50 years of age who did not have any serious ophthalmic disorders were recruited from four community free clinics. The free clinics were in parks from the Yuexiu and Tianhe Districts of Guangzhou. They provide primary eye care services for inhabitants who participate in daily outdoor activities in the park. Subjects were approached at random by healthcare workers and invited for a primary eye care services at the free clinics. These inhabitants were selected because they were a stable and an older population that was representative of Guangzhou. The subjects were identified by systematic sampling (every fifth patient registered at the free clinic) and asked to participate in the study after they provided written informed consent. A detailed questionnaire including demographic information, socioeconomic details, and medical and ocular histories was administered.
Examination of subjects was performed between September 2013 and July 2014. All study procedures were performed in accordance with the tenets of the Declaration of Helsinki, and the study was approved by the Ethics Committee of the Zhongshan Ophthalmic Center.

\section{Procedures}

A summary of the enrollment and study procedures is shown in Fig. 1. All participants had a standardized slit lamp examination. Inclusion criteria were as follows: the absence of uncontroled systemic illness, intraocular pressure of $21 \mathrm{mmHg}$ or less, and normal findings on slit lamp examination and fundus examinations. In eyes with early cataracts, only patients with at least $20 / 40$ visual acuity were included. Exclusion criteria were previous ocular surgery, a history of corneal disease, contact lens wear, and dry eye that complicated the examination. The examinations were performed by skilled operators who were trained before the study.

The AL, ACD, and $\mathrm{K}$ were measured with noncontact partial coherence laser interferometry (IOL Master, version 3.01; Carl Zeiss Meditec, Jena, Germany). The validity and repeatability of the IOL Master measurements have been previously reported [1]. AL measurements

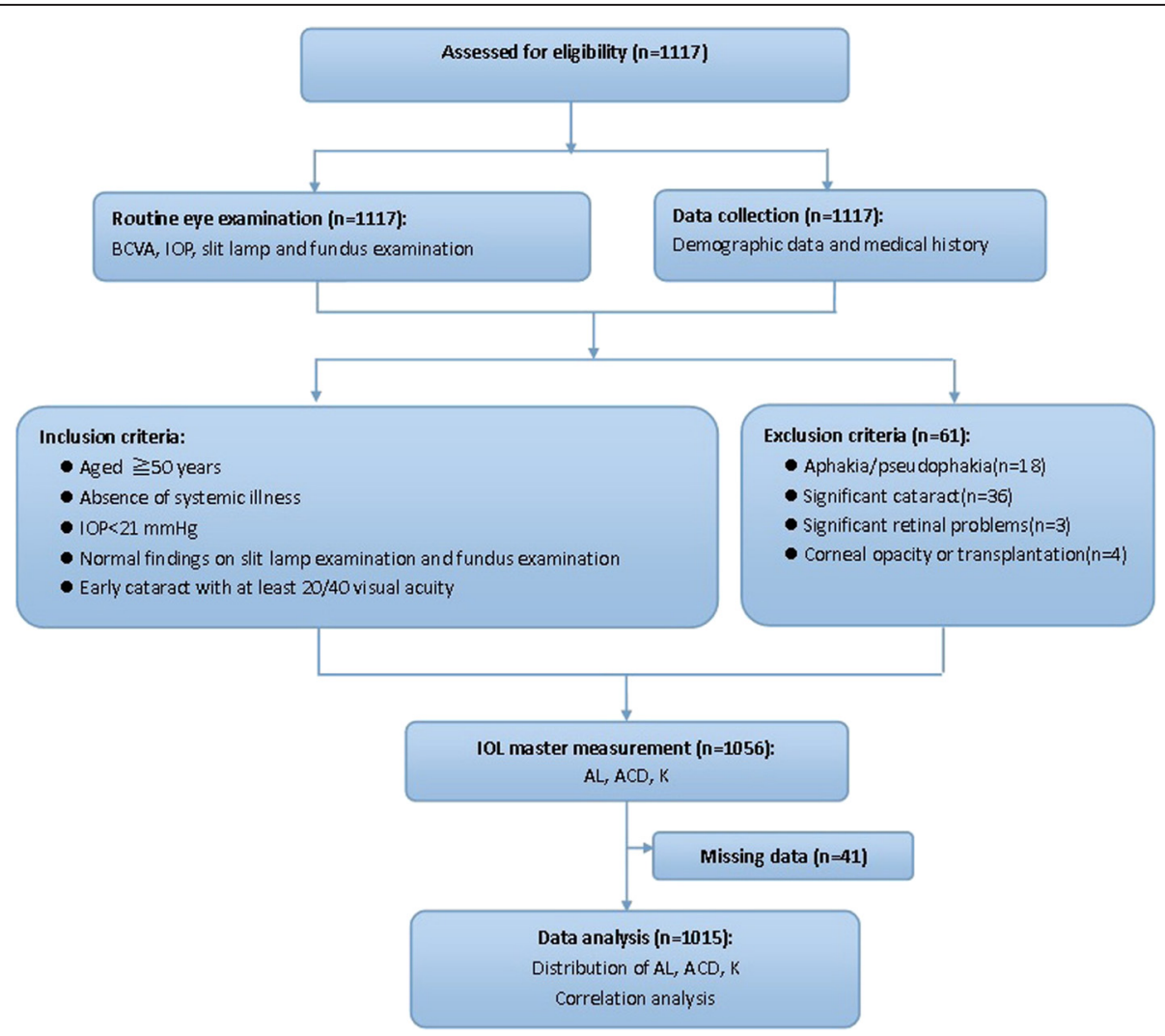

Fig. 1 Summary of the trial design 
were performed a minimum of five times in each eye (minimum signal/noise ratio of 100), and a standard deviation of $0.15 \mathrm{~mm}$ for $\mathrm{AL}$ was required. Three keratometric measurements were made in an automated mode and the mean calculated by the device was used for further analyses. Corneal power was measured in two meridians, the greatest and least radii of curvature (K1, K2). Keratometric data were reported as corneal power in diopters (D). The refractive index value used for this conversion by the IOL Master was $n=1.3375$. Subsequent to keratometric measurements, ACD was also measured a minimum of three times, and $0.13 \mathrm{~mm}$ for ACD was required for optimal scans. If subjects had poor visual acuity, poor fixation and high myopia which would make measurements varied, then measurements were repeated until reproducible results were obtained. All patients were tested by the same experienced examiner.

\section{Statistical analysis}

Statistical analysis was performed using SPSS software, version 19.0 (SPSS, Chicago, IL, USA). The KolmogorovSmirnov test was used to evaluate the normality of the distribution for all variables. Because the biometric data of the left and right eyes were similar $(P>0.05)$, the right eyes were arbitrarily chosen to represent a specific individual. Analysis of variance was conducted to evaluate the variation in different biometric components.
Correlations between AL and other biometric variables were calculated using Pearson's correlation coefficient, and $95 \%$ confidence intervals (CIs) were reported. Group trend tests were used to assess any significant trends across age groups for each variable.

\section{Results}

We initially examined 1,117 subjects. Data from 102 subjects who did not fulfill the study criteria were eliminated, including aphakia/pseudophakia (18 eyes), significant cataracts (36 eyes), significant retinal problems (three eyes), corneal opacity or transplantation (four eyes), and 41 additional subjects who had missing data. Finally, data from 1,015 subjects were analyzed. There were no differences between subjects included in our analyses and those excluded because of age $(P=0.064)$ or sex $(P=0.254)$.

The mean AL was $23.48 \mathrm{~mm}$ (95\% CI, 23.40-23.55), the mean ACD was $3.03 \mathrm{~mm}$ (95\% CI, 3.01-3.05), the mean $\mathrm{K} 1$ was $43.79 \mathrm{D}$ (95\% CI, 43.70-43.87), the mean K2 was $44.63 \mathrm{D}$ (95\% CI, 44.54-44.72), and the mean K was $44.20 \mathrm{D}$ (95\% CI, 44.11-44.29). Table 1 shows the mean $\mathrm{AL}$ and other biometric parameters stratified by age and sex. Figure 2 shows a histogram of the distribution of AL, ACD, and K. The Kolmogorov-Smirnov test results indicated a significant difference from normal distributions $(P<0.05)$ of $\mathrm{AL}$ and $\mathrm{K}$. According

Table 1 Age and gender distribution of ocular biometry measures with $95 \%$ confidence intervals

\begin{tabular}{|c|c|c|c|c|c|c|c|}
\hline \multirow[b]{2}{*}{ Age group(years) } & \multirow[b]{2}{*}{$n$} & \multirow[b]{2}{*}{$\mathrm{AL}(\mathrm{mm})$} & \multirow[b]{2}{*}{$\mathrm{ACD}(\mathrm{mm})$} & \multicolumn{4}{|l|}{$C C(D)$} \\
\hline & & & & K1 & $\mathrm{K} 2$ & K & $\Delta K$ \\
\hline \multicolumn{8}{|l|}{ Gender } \\
\hline \multicolumn{8}{|l|}{ Men } \\
\hline $50-59$ & 80 & 23.61(20.93-28.84) & $3.14(2.27-4.01)$ & 43.75(40.08-46.68) & $44.43(41.11-48.28)$ & $44.08(40.59-47.47)$ & $0.68(0.06-3.05)$ \\
\hline $60-69$ & 244 & 23.83(20.89-30.34) & $3.15(2.27-4.01)$ & 43.41(36.49-49.06) & $44.21(41.16-50.45)$ & $43.81(40.23-49.74)$ & $0.80(0.00-8.33)$ \\
\hline 70-79 & 117 & 23.97(21.40-29.03) & $3.13(1.97-4.16)$ & $43.26(39.57-47.07)$ & $44.25(40.56-48.35)$ & 43.75(40.30-47.70) & $0.99(0.11-3.57)$ \\
\hline $80+$ & 26 & 23.54(22.03-24.92) & $2.91(1.90-3.59)$ & 43.23(39.99-46.30) & $44.86(42.94-47.8)$ & $44.02(41.46-46.97)$ & $1.63(0.29-3.14)$ \\
\hline All & 467 & 23.81(20.89-30.34) & $3.13(1.90-4.16)$ & 43.42(36.49-49.06) & $44.29(40.56-50.45)$ & 43.85(40.23-49.74) & $0.87(0.00-8.33)$ \\
\hline \multicolumn{8}{|l|}{ Women } \\
\hline $50-59$ & 117 & 23.04(20.88-31.15) & $2.93(2.14-4.10)$ & $44.16(40.42-48.49)$ & $44.92(42.45-49.71)$ & $44.54(42.06-49.09)$ & $0.76(0.00-4.64)$ \\
\hline $60-69$ & 289 & 23.22(20.62-29.27) & $2.96(2.14-4.10)$ & $44.11(40.76-47.94)$ & $44.89(41.31-49.41)$ & $44.49(41.03-48.35)$ & $0.78(0.00-3.42)$ \\
\hline $70-79$ & 129 & $23.26(21.53-29.23)$ & $2.96(2.19-3.95)$ & $43.98(40.27-48.01)$ & $44.92(40.52-49.56)$ & $44.44(40.39-48.77)$ & $0.94(0.16-3.81)$ \\
\hline $80+$ & 13 & $23.13(22.27-24.54)$ & $2.88(2.28-3.62)$ & $44.25(41.36-49.13)$ & $45.18(42.24-50.22)$ & $44.71(41.80-49.67)$ & $0.93(0.24-2.38)$ \\
\hline All & 548 & 23.19(20.62-31.15) & $2.95(2.14-4.10)$ & $44.09(40.27-49.13)$ & $44.91(40.52-50.22)$ & $44.50(40.39-49.67)$ & $0.82(0.00-4.64)$ \\
\hline \multicolumn{8}{|l|}{ Whole population } \\
\hline $50-59$ & 197 & 23.27(20.88-31.15) & $3.02(2.14-4.10)$ & 43.99(40.08-48.49) & $44.72(41.11-49.71)$ & 44.35(40.59-49.09) & $0.73(0-4.64)$ \\
\hline $60-69$ & 533 & $23.50(20.62-30.34)$ & $3.04(2.10-4.01)$ & 43.64(36.49-49.06) & $44.58(41.16-50.45)$ & $44.18(40.23-49.74)$ & $0.79(0-8.33)$ \\
\hline $70-79$ & 246 & $23.60(21.40-29.23)$ & $3.04(1.97-4.16)$ & $43.57(39.57-48.01)$ & $44.60(40.52-49.56)$ & $44.11(40.30-48.77)$ & $0.96(0.11-3.81)$ \\
\hline $80+$ & 39 & $23.41(22.03-24.92)$ & $2.90(1.90-3.62)$ & 43.78(39.99-49.13) & $44.96(42.24-50.22)$ & $44.25(41.46-49.67)$ & $1.40(0.24-3.14)$ \\
\hline All & 1015 & $23.48(23.40-23.55)$ & $3.03(3.01-3.05)$ & $43.79(43.70-43.87)$ & $44.63(44.54-44.72)$ & $44.20(44.11-44.29)$ & $0.84(0.80-0.88)$ \\
\hline
\end{tabular}

$A C D$ anterior chamber depth, $A L$ axial length, $C C$ corneal curvature, $D$ diopters, $\mathrm{mm}$ millimeters 

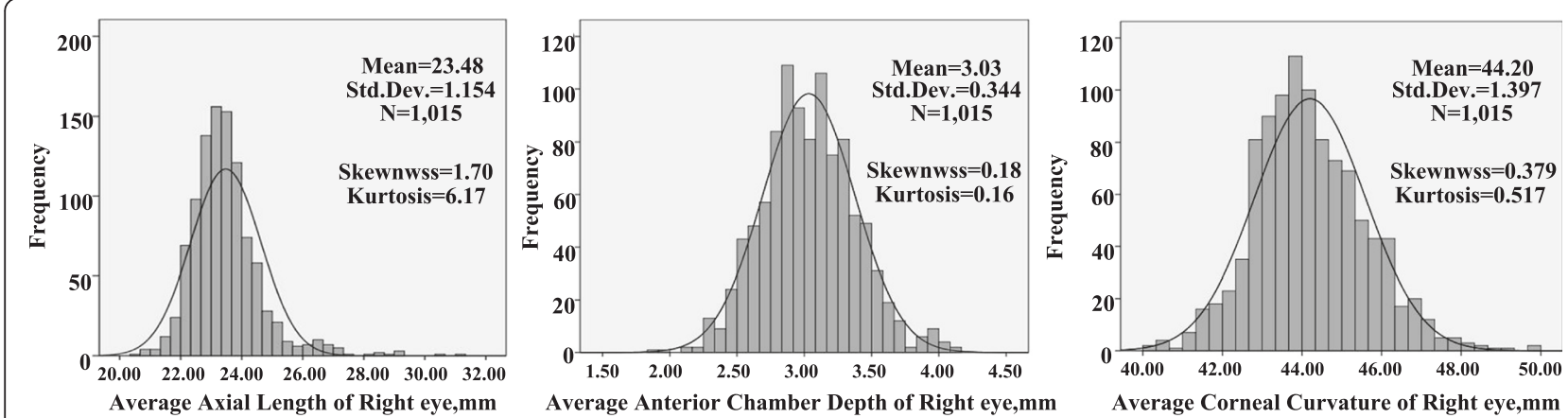

Fig. 2 Distribution of axial length, anterior chamber depth, and corneal curvatures

to the distribution indices, $\mathrm{AL}$ and $\mathrm{K}$ had leptokurtic distributions.

The ACD decreased across age groups in male subjects $(P=0.002)$, but there was no significant age-related change in AL and $\mathrm{K}(P=0.411, P=0.614$, respectively) (Fig. 3). After adjustment for age, the AL was significantly longer in male subjects than in female subjects (23.81 $\mathrm{mm}$ versus $23.19 \mathrm{~mm} ; P=0.020$ ). The mean ACD was deeper in male $(3.13 \mathrm{~mm})$ than in female subjects $(2.95 \mathrm{~mm} ; P<0.001)$. Female subjects had a steeper $\mathrm{K}$ than male subjects $(44.50 \mathrm{~mm}$ versus $43.85 \mathrm{~mm}$; $P<0.001)$.

ACD correlated positively with AL $(r=0.652, P<0.001)$. The $\mathrm{K}$ was correlated with ACD $(r=-0.266, P<0.001)$. There was also a significant negative correlation between $\mathrm{AL}$ and $\mathrm{K}(r=-0.437, P<0.001)$ and a higher astigmatism was associated with shallower ACD $(r=-0.064, P<0.05)$.

\section{Discussion}

Our study provides population-based cross-sectional normative data on $\mathrm{AL}, \mathrm{ACD}$, and $\mathrm{K}$ based on IOL Master measurements of an adult population, 50-98 years of age, from urban South China. In this study, we confirmed previous data that AL and ACD were not normally distributed in the older population [7]. We also found that older male subjects had a shallower ACD, and female subjects had a shorter AL, shallower ACD, and steeper $\mathrm{K}$ than male subjects. These patterns are similar to those observed in a Chinese population study conducted in Singapore and mainland China that used similar protocols but measured biometry with A-scan ultrasound, rather than the IOL Master [8, 9]. However, as we described in a previous study, we did not observe any age-specific differences in $\mathrm{AL}$ and $\mathrm{K}$ in this population [6].

The normal ranges of ocular parameters are important in the formulas used for intraocular lens calculations for cataract surgery. However, the distribution of AL in the normal population in South China determined by the IOL Master has not been reported. The mean AL in the present study $(23.48 \mathrm{~mm})$ was shorter than that of cataractous eyes $(23.60 \mathrm{~mm})$ reported in our previous study. When compared with other population-based surveys (Table 2), it is longer than reported in the Tanjong Pagar Study in Singaporean Chinese $(23.23 \mathrm{~mm})$, in the Liwan Study in South China $(23.11 \mathrm{~mm})[8,9]$, and also longer than the studies in India [10], Mongolia [11], and Burma [12]. It was almost identical to the AL of Caucasians [7, 13], but shorter than the AL reported in the Beaver Dam Eye Study [(BDES); $23.69 \mathrm{~mm}$ ] and in the EPIC-Norfolk Study from England $(23.80 \mathrm{~mm})[14,15]$. These differences may be due to different calibrations of the devices such as the IOL Master and ultrasound used to obtain biometry values. In addition, our study showed that the

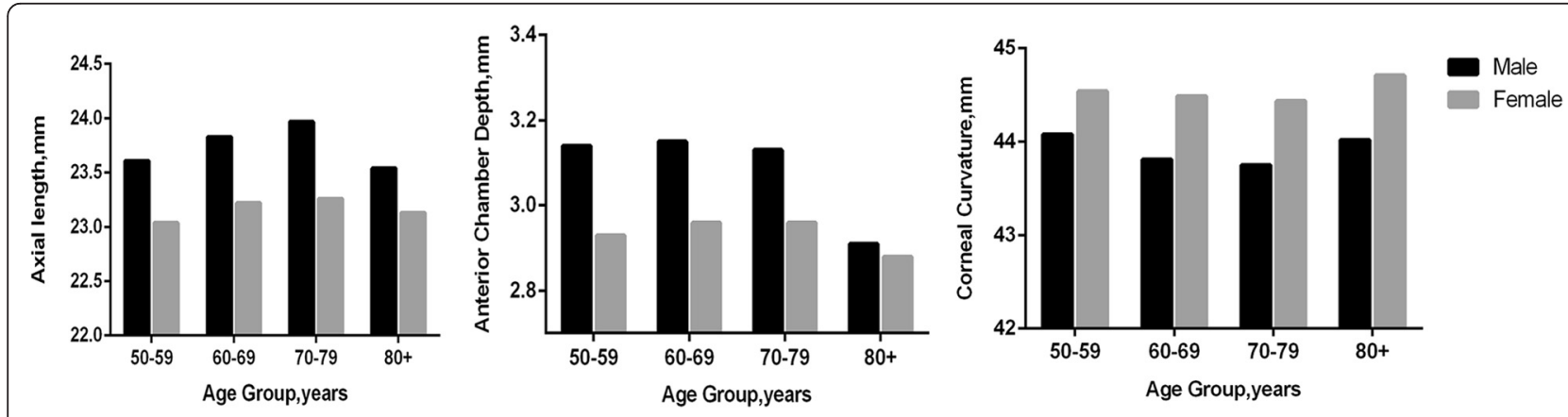

Fig. 3 Frequency distribution of the sample by age group 
Table 2 Mean axial length, anterior chamber depth, corneal and curvature radius reported in population-based studies

\begin{tabular}{|c|c|c|c|c|c|c|c|c|c|c|c|}
\hline \multirow[b]{2}{*}{ Study } & \multirow[b]{2}{*}{ Ethnicity } & \multirow[b]{2}{*}{ Measurement } & \multicolumn{3}{|l|}{$\mathrm{AL}$} & \multicolumn{3}{|l|}{ ACD } & \multicolumn{3}{|l|}{ CC } \\
\hline & & & Men & Women & All & Men & Women & All & Men & Women & All \\
\hline The Los Angeles Latino Eye Study & Latinos & Ultrasound & 23.65 & 23.18 & 23.38 & 3.48 & 3.36 & 3.41 & 43.35 & 43.95 & 43.72 \\
\hline The Mongolian Study & Mongolians & Ultrasound & 23.43 & 23.08 & 23.13 & 2.87 & 2.77 & & 43.65 & 44.24 & \\
\hline The Beaver Dam Eye Study & white & IOL Master & 23.92 & 23.51 & 23.69 & 3.14 & 3.09 & 3.11 & $7.77^{\mathrm{a}}$ & $7.65^{a}$ & $7.70^{\mathrm{a}}$ \\
\hline The Meiktila Eye Study & Burmese & Ultrasound & 23.12 & 22.54 & 22.76 & 2.86 & 2.79 & 2.82 & $7.71^{\mathrm{a}}$ & $7.56^{\mathrm{a}}$ & $7.62^{\mathrm{a}}$ \\
\hline The Reykjavik Study & White & Ultrasound & 23.74 & 23.20 & & 3.20 & 3.08 & & 43.41 & 43.73 & \\
\hline The Liwan Eye Study & Chinese & Ultrasound & 23.38 & 22.83 & 23.11 & 2.75 & 2.61 & 2.67 & 43.50 & 44.25 & 43.88 \\
\hline The tanjong pagar study & Chinese & Ultrasound & 23.54 & 22.98 & 23.23 & 2.99 & 2.81 & 2.90 & $7.73^{\mathrm{a}}$ & $7.59^{\mathrm{a}}$ & $7.65^{\mathrm{a}}$ \\
\hline The Singapore Malay Eye Study & Malay & IOL Master & & & 23.55 & & & 3.10 & & & $7.65^{\mathrm{a}}$ \\
\hline The Singapore Indian Eye Study & Indians & IOL Master & 23.68 & 23.23 & 23.45 & 3.19 & 3.10 & 3.15 & $7.68^{\mathrm{a}}$ & $7.55^{\mathrm{a}}$ & $7.61^{\mathrm{a}}$ \\
\hline The blue mountain eye study & white & IOL Master & 23.75 & 23.20 & 23.44 & 3.16 & 3.06 & 3.10 & 43.01 & 43.74 & 43.42 \\
\hline
\end{tabular}

$A C D$ anterior chamber depth, $A L$ axial length, $C C$ corneal curvature;

${ }^{a}$ Corneal curvature in $\mathrm{mm}$

AL distribution was slightly skewed to the right and had a leptokurtic distribution. This finding is consistent with data from previous studies of refractive error in China $[3,9]$. The abnormal distribution of greater AL could be attributed to the high myopic refractive error in this population.

The mean ACD $(3.03 \mathrm{~mm})$ from our study is deeper than in the Chinese, Liwan, $(2.67 \mathrm{~mm})$, and Tanjong Pargar Studies $(2.90 \mathrm{~mm})$, but shallower compared with the Caucasian population $(3.11 \mathrm{~mm})$ [7-9]. Compared with the A-scan ultrasound, AL measured by the IOL Master has been reported to be significantly longer and more accurate [16-18]. ACD measured by ultrasound was found to be significantly shorter compared with noncontact measuring systems [19]. Additionally our population was slightly older.

In contrast to the trend of longer ALs in younger people from other populations, we did not observe any age-specific differences in ALs in our population $[8,11,20]$. Consistent with our study, the Los Angeles Latino Eye Study and the Liwan Study did not show an association between AL and age $[9,13]$. However, the AL increased with increasing age in the Central Indian Eye and Medical Study and the Mongolian Study [10, 11]. One explanation for this discrepancy is that the age-related differences in AL may be attributed to a cohort effect rather to an actual reduction of AL with age. It is possible that once the eye has achieved its adult size, insignificant change occurs in the AL during adulthood aging. In the BDES and The Singapore Malay Eye Study (SiMES), after adjusting for height and education, the association between age and AL was insignificant, suggesting a cohort effect caused by socioeconomic background and stature development $[14,21]$. ACD was also negatively correlated with age in male but not in female subjects, whereas ACD has been reported to decrease with age in both sexes in other populations [7, 21]. The agespecific trend in ACD can be explained by an agerelated increase in lens thickness [22]. It is also possible that the flattening of the ACD observed in our studies may result from a cohort effect involving younger individuals, especially male subjects, who may be exposed to more near work and become more myopic with a deeper ACD.

In our study, there was no correlation between $\mathrm{K}$ and age. However, a trend for age-related increases of $\mathrm{K}$ has been reported in young subjects. Hayashi et al. reported that the degree of both horizontal and vertical corneal curvatures increases with age [23]. Consistent with our study, Lee et al. reported that after adjusting for the effects of other parameters, changes in corneal curvature did not have a statistically significant correlation with age [24].

Regarding sex variations, we observed that male subjects had longer eyes, deeper anterior chambers, and flatter corneas than female subjects as measured by the IOL Master. The BDES reported that male subjects had longer ALs and larger eyes, but these differences were not significant after adjustment for height [14]. However, the SiMES reported that sex differences in AL and ACD were still significant when using multivariate analyses and controlling for stature, suggesting that sex may be an independent determinant of the AL [21]. Taken together, the results from multiple reports suggest that genetic and other factors may account for the differences in biometry between male and female subjects.

In our study, the AL and ACD were significantly correlated, indicating that a longer $\mathrm{AL}$ or higher levels of myopia are associated with steeper corneas. We also found a significant negative correlation of $K$ with $A L$, which has been reported in other studies $[25,26]$. The inverse correlation with $\mathrm{AL}$ can be attributed to the 
emmetropization mechanism that compensates for a higher AL by decreasing the corneal power [27]. In addition, higher astigmatism was associated with steeper ACD. To our knowledge, this relationship has not been previously reported.

Our study provides population-based data and examines a homogeneous population. It avoids a potential bias associated with clinic-based studies, and excludes confounding variables such as small sample size and differing methodologies [28]. Furthermore, the biometric measurements were performed by the IOL Master that has been proven to be a better predictor of normative ocular biometric data than ultrasound biometry [29]. However, the cross-sectional nature of our study is a limitation in assessing age-related changes of biometric characteristics because any apparent trend may result from a cohort effect rather than a longitudinal agerelated change.

\section{Conclusions}

In conclusion, this study provides normative ocular biometry data and their interrelationships for a large representative older population in South China. Age and sex variations in ocular biometry were observed in this population, with older people generally having a shallower ACD and flatter K, while male subjects had longer eyes, deeper anterior chambers, and flatter corneas than female subjects. Eyes with axial elongation tended to have flatter corneas and deeper anterior chambers. Furthermore, measurements by the IOL Master indicated that age and sex were the most consistent predictors of ocular biometry in the adult population of South China.

\section{Ethics approval and consent to participate}

All study procedures were performed in accordance with the tenets of the Declaration of Helsinki, and the study was approved by the Ethics Committee of the Zhongshan Ophthalmic Center. Written informed consent was obtained from all the study participants.

\section{Consent for publication}

Not applicable.

\section{Availability of data and materials}

All the data supporting the conclusions of this article is included within the article.

\section{Abbreviations}

ACD: anterior chamber depth; AL: axial length; BDES: Beaver Dam Eye Study; D: diopters; IOL: intraocular lens; K: corneal curvature; SiMES: The Singapore Malay Eye Study.

\section{Competing interests}

The authors declare that they have no competing interests.

\section{Authors' contributions}

$\mathrm{HC}$ participated in the interpretation of data, performed the statistical analysis and drafted the manuscript; WC conceived of the study, and participated in its design and coordination, critically revised the manuscript; HL participated in the interpretation of data and critically revised the manuscript; $\mathrm{ZL}$ and $\mathrm{JC}$ participated in the interpretation of data and performed the statistical analysis. All authors read and approved the final manuscript.

\section{Acknowledgements}

We thank numerous individuals participated in this study.

\section{Funding}

This study was supported by a grant from the National Natural Science Foundation (81300784).

Received: 3 February 2015 Accepted: 15 April 2016

Published online: 01 May 2016

\section{References}

1. Verhulst E, Vrijghem JC. Accuracy of intraocular lens power calculations using the Zeiss IOL master. A prospective study. Bull Soc Belge Ophtalmol. 2001;281:61-5.

2. Saka N, Ohno-Matsui K, Shimada N, Sueyoshi S, Nagaoka N, Hayashi W, Hayashi K, Moriyama M, Kojima A, Yasuzumi K, et al. Long-term changes in axial length in adult eyes with pathologic myopia. Am J Ophthalmol. 2010; 150:562-8. e561.

3. Shen $P$, Zheng $Y$, Ding $X$, Liu B, Congdon N, Morgan I, He M. Biometric measurements in highly myopic eyes. J Cataract Refract Surg. 2013;39:180-7.

4. Kang HM, Lee CS, Park HJ, Lee KH, Byeon SH, Koh HJ, Lee SC. Characteristics of rhegmatogenous retinal detachment after refractive surgery: comparison with myopic eyes with retinal detachment. Am J Ophthalmol. 2014;157: 666-72. e661-662.

5. Zaldivar R, Shultz MC, Davidorf JM, Holladay JT. Intraocular lens power calculations in patients with extreme myopia. J Cataract Refract Surg. 2000; 26:668-74.

6. Chen W, Zuo C, Chen C, Su J, Luo L, Congdon N, Liu Y. Prevalence of corneal astigmatism before cataract surgery in Chinese patients. J Cataract Refract Surg. 2013;39:188-92.

7. Fotedar R, Wang JJ, Burlutsky G, Morgan IG, Rose K, Wong TY, Mitchell P. Distribution of axial length and ocular biometry measured using partial coherence laser interferometry (IOL Master) in an older white population. Ophthalmology. 2010;117:417-23.

8. Wong TY, Foster PJ, Ng TP, Tielsch JM, Johnson GJ, Seah SK. Variations in ocular biometry in an adult Chinese population in Singapore: the Tanjong Pagar Survey. Invest Ophthalmol Vis Sci. 2001:42:73-80.

9. He M, Huang W, Li Y, Zheng Y, Yin Q, Foster PJ. Refractive error and biometry in older Chinese adults: the Liwan eye study. Invest Ophthalmol Vis Sci. 2009;50:5130-6.

10. Nangia $V$, Jonas JB, Sinha A, Matin A, Kulkarni M, Panda-Jonas S. Ocular axial length and its associations in an adult population of central rural India: the Central India Eye and Medical Study. Ophthalmology. 2010;117:1360-6.

11. Wickremasinghe $S$, Foster PJ, Uranchimeg D, Lee PS, Devereux JG, Alsbirk PH, Machin D, Johnson GJ, Baasanhu J. Ocular biometry and refraction in Mongolian adults. Invest Ophthalmol Vis Sci. 2004;45:776-83.

12. Warrier S, Wu HM, Newland HS, Muecke J, Selva D, Aung T, Casson RJ. Ocular biometry and determinants of refractive error in rural Myanmar: the Meiktila Eye Study. Br J Ophthalmol. 2008;92:1591-4.

13. Shufelt C, Fraser-Bell S, Ying-Lai M, Torres M, Varma R, Los Angeles Latino Eye Study G. Refractive error, ocular biometry, and lens opalescence in an adult population: the Los Angeles Latino Eye Study. Invest Ophthalmol Vis Sci. 2005;46:4450-60.

14. Klein BE, Klein R, Moss SE. Correlates of lens thickness: the Beaver Dam Eye Study. Invest Ophthalmol Vis Sci. 1998:39:1507-10.

15. Foster PJ, Broadway DC, Hayat S, Luben R, Dalzell N, Bingham S, Wareham NJ, Khaw KT. Refractive error, axial length and anterior chamber depth of the eye in British adults: the EPIC-Norfolk Eye Study. Br J Ophthalmol. 2010;94:827-30.

16. Santodomingo-Rubido J, Mallen EA, Gilmartin B, Wolffsohn JS. A new noncontact optical device for ocular biometry. Br J Ophthalmol. 2002;86:458-62. 
17. Nemeth J, Fekete O, Pesztenlehrer N. Optical and ultrasound measurement of axial length and anterior chamber depth for intraocular lens power calculation. J Cataract Refract Surg. 2003;29:85-8.

18. Lam AK, Chan R, Pang PC. The repeatability and accuracy of axial length and anterior chamber depth measurements from the IOLMaster. Ophthalmic Physiol Opt. 2001;21:477-83.

19. Reddy AR, Pande MV, Finn P, El-Gogary H. Comparative estimation of anterior chamber depth by ultrasonography, Orbscan II, and IOLMaster. J Cataract Refract Surg. 2004;30:1268-71.

20. Eysteinsson T, Jonasson F, Arnarsson A, Sasaki H, Sasaki K. Relationships between ocular dimensions and adult stature among participants in the Reykjavik Eye Study. Acta Ophthalmol Scand. 2005;83:734-8.

21. Lim LS, Saw SM, Jeganathan VS, Tay WT, Aung T, Tong L, Mitchell P, Wong TY. Distribution and determinants of ocular biometric parameters in an Asian population: the Singapore Malay eye study. Invest Ophthalmol Vis Sci. 2010;51:103-9.

22. Brown NP, Koretz JF, Bron AJ. The development and maintenance of emmetropia. Eye (Lond). 1999;13:83-92.

23. Hayashi $\mathrm{K}$, Hayashi H, Hayashi F. Topographic analysis of the changes in corneal shape due to aging. Cornea. 1995;14:527-32.

24. Lee DW, Kim JM, Choi CY, Shin D, Park KH, Cho JG. Age-related changes of ocular parameters in Korean subjects. Clin Ophthalmol. 2010;4:725-30.

25. Carney LG, Mainstone JC, Henderson BA. Corneal topography and myopia. A cross-sectional study. Invest Ophthalmol Vis Sci. 1997;38:311-20.

26. Fledelius HC. Corneal curvature radius. Oculometric considerations with reference to age and refractive change. Acta Ophthalmol Suppl. 1988;185:74-7.

27. Ishii K, Iwata H, Oshika T. Quantitative evaluation of changes in eyeball shape in emmetropization and myopic changes based on elliptic fourier descriptors. Invest Ophthalmol Vis Sci. 2011;52:8585-91.

28. Wong TY, Hyman L. Population-based studies in ophthalmology. Am J Ophthalmol. 2008;146:656-63.

29. Goyal R, North RV, Morgan JE. Comparison of laser interferometry and ultrasound A-scan in the measurement of axial length. Acta Ophthalmol Scand. 2003;81:331-5.

\section{Submit your next manuscript to BioMed Central and we will help you at every step:}

- We accept pre-submission inquiries

- Our selector tool helps you to find the most relevant journal

- We provide round the clock customer support

- Convenient online submission

- Thorough peer review

- Inclusion in PubMed and all major indexing services

- Maximum visibility for your research

Submit your manuscript at www.biomedcentral.com/submit

C Biomed Central 